\title{
Production and futures hedging with state-dependent background risk
}

\author{
Kit Pong Wong* \\ School of Economics and Finance, University of Hong Kong, Pokfulam Road, Hong Kong
}

\begin{abstract}
This paper examines the production and futures hedging decisions of the competitive firm under output price uncertainty and with state-dependent background risk. We show that the firm's optimal production decision is independent of the underlying uncertainty and of the firm's risk attitude. We further show that the firm's optimal futures position is a full-hedge that completely eliminates the output price risk if either the background risk is state-independent, or the firm's utility function is quadratic. When the firm's preferences exhibit prudence, an under-hedge or an over-hedge is optimal should the magnitude of the background risk vary in a monotonic manner with changes in the realized state. When the prudent firm has access not only to the unbiased futures contracts but also to fairly priced options, we construct a reasonable example wherein the firm optimally includes the options in its hedge position. Hence, we offer a rationale for the hedging role of options, which is over and above that of futures, in the case of state-dependent background risk.
\end{abstract}

JEL classification: D21; D81; G13

Keywords: Futures; Production; Prudence; State-dependent background risk

\section{Introduction}

Since the seminal work of Sandmo (1971), the literature has extensively examined the behavior of the competitive firm under output price uncertainty when a futures market exists for hedging purposes, from which two celebrated results emanate (see, e.g., Broll and Eckwert, 2000; Danthine, 1978; Feder et al., 1980; Holthausen, 1979; Wong, 2006, 2007). First, the separation theorem states that the firm's production decision depends neither on the firm's risk preferences nor on the output price uncertainty. Second, the full-hedging theorem states that the firm's optimal futures position is a full-hedge that completely elim-

\footnotetext{
${ }^{*}$ Tel.: +852 2859 1044; fax: +852 25481152 .

E-mail address: kpwong@econ.hku.hk (K.P. Wong).
} 
inates the output price risk should the futures market be unbiased. ${ }^{1}$ A corollary of the full-hedging theorem is that no other hedging instruments, options in particular, would have a hedging role that is over and above that of futures, rendering futures to be the most preferred hedging instrument (see Battermann et al., 2000). ${ }^{2}$

This paper contributes to the extant literature by incorporating additional sources of uncertainty, aggregated into a single source referred to as background risk. Examples of background risk abound. Some of the initial wealth of the competitive firm may be held in risky assets and thus creates an additional source of uncertainty (see Chavas, 1985). The fixed cost of the competitive firm may also be random because the firm's physical assets can be ruined by natural disasters or fire (see Machnes, 1993; Wong, 1995). Briys et al. (1993) show that the full-hedging theorem holds in the presence of background risk should the background risk be independent of the output price risk. Since the unbiased futures contracts cannot cross-hedge the independent background risk, it remains optimal to completely eliminate the output price risk via a full-hedge.

In this paper, we follow Fei and Schlesinger (2008) to allow background risk to be statedependent. For example, weather affects not only the supply of the commodity produced by the competitive firm, thereby the output price, but also the magnitude of losses when the firm's physical assets are on fire. To this end, we consider a continuum of states of nature such that the state and the output price are correlated. As in Fei and Schlesinger (2008), we model state-dependent background risk by two components: (i) a zero-mean random variable that is independent of both the state of nature and the output price; and (ii) a positive deterministic function of the realized state, which gauges the magnitude of the background risk. ${ }^{3}$

Since the competitive firm's production decision does not depend on the underlying

\footnotetext{
${ }^{1}$ The full-hedging theorem is analogous to a well-known result in the insurance literature that a risk-averse individual fully insures at an actuarially fair price (see Mossin, 1968).

${ }^{2}$ Indeed, as shown by Lapan et al. (1991), the competitive firm uses options only when the futures price and/or option premiums are perceived as biased by the firm. In this regard, options act more like a speculative device rather than a hedging instrument.

${ }^{3}$ Fei and Schlesinger (2008) consider the discrete case that background risk in the loss event is different from that in the no-loss event. Unlike them, we allow background risk to vary in a continuous manner with respect to the continuum of states of nature.
} 
uncertainty when a futures market exists for hedging purposes, the separation theorem remains intact when the state-dependent background risk is imposed onto the firm. We further show that the full-hedging theorem holds if either the background risk is stateindependent, or the firm's utility function is quadratic. When the firm's preferences exhibit the more reasonable property of prudence (see Kimball, 1990, 1993) and the background risk is state-dependent, we invalidate the full-hedging theorem if the magnitude of the background risk varies in a monotonic manner with changes in the realized state. As shown in Kimball (1990), prudence creates the demand for precautionary saving in that prudent individuals would like to shift more wealth to a later period (i.e., save more) to better cope with the risk arising from uncertain labor income earned at that time. Similar intuition applies to our model that the competitive firm, being prudent, would like to shift its profits from the states with small background risk into the states with large background risk. The optimal future position is devised to serve both hedging and precautionary purposes, thereby making an under-hedge or an over-hedge optimal depending on how the magnitude of the background risk varies with changes in the realized state. When the prudent firm has access not only to the unbiased futures contracts but also to fairly priced options, we construct a reasonable example wherein the firm optimally includes the options in its hedge position. Whether the firm opts for a long or short option position depends on the risk attitude of the firm, the joint distribution of the output price and the state variable, and the relation between the background risk and the realized state in a rather complicated manner. This paper as such provides a rationale for the hedging role of options in the case of state-dependent background risk. ${ }^{4}$

The rest of this paper is organized as follows. Section 2 delineates the model of the competitive firm under output price uncertainty and with state-dependent background risk. The firm has access to unbiased futures contracts to hedge its output price risk exposure. Section 3 characterizes the firm's optimal production decision. Section 4 derives the firm's optimal futures position. Section 5 constructs a reasonable example that shows the hedging role of options. The final section concludes.

\footnotetext{
${ }^{4}$ Machnes (1992) and Wong (2002) restrict the competitive firm to use options only for hedging purposes, thereby failing to show the hedging role of options.
} 


\section{The model}

Consider the competitive firm under output price uncertainty à la Sandmo (1971). The firm makes its decisions in a one-period horizon with two dates, 0 and 1 . There is a continuum of states of nature specified by the interval, $[\underline{S}, \bar{S}]$, with $\underline{S}<\bar{S}$. The state of nature, $\tilde{S}$, is regarded as a random variable at date 0 with the known cumulative distribution function, $G(S)$, over support $[\underline{S}, \bar{S}] . .^{5}$ The true value of $\tilde{S}$ is publicly revealed at date 1 .

To begin, the firm produces a single commodity according to a deterministic cost function, $C(Q)$, where $Q \geq 0$ is the output level chosen by the firm at date 0 , and $C(Q)$ is compounded to date 1 . The firm's production technology exhibits decreasing returns to scale, leading the cost function, $C(Q)$, to possess the properties that $C(0)=C^{\prime}(0)=0$, and $C^{\prime}(Q)>0$ and $C^{\prime \prime}(Q)>0$ for all $Q>0$. The firm sells its entire output, $Q$, at date 1 at the then prevailing spot price, $\tilde{P}$, that is not known ex ante. Conditional on the realized state being $S \in[\underline{S}, \bar{S}]$, let $F(P \mid S)$ be the cumulative distribution function of $\tilde{P}$ over support $[\underline{P}, \bar{P}]$, where $0<\underline{P}<\bar{P}$. To hedge such output price risk, the firm can trade infinitely divisible futures contracts at date 0 , each of which calls for delivery of one unit of the commodity at date 1 at the predetermined futures price, $P^{f} \in(\underline{P}, \bar{P}) .{ }^{6}$ Let $X$ be the number of the futures contracts sold (purchased if negative) by the firm at date 0 .

Besides the output price risk, $\tilde{P}$, the firm faces an additional source of uncertainty (hereafter referred to as background risk), $\beta(S) \tilde{Z}$, where $\tilde{Z}$ is a zero-mean random variable independent of $\tilde{P}$, and $\beta(S)$ is a positive function of the realized state, $S$. Let $H(Z)$ be the cumulative distribution function of $\tilde{Z}$ over support $[\underline{Z}, \bar{Z}]$, where $\underline{Z}<0<\bar{Z}$. The background risk, $\beta(S) \tilde{Z}$, is state-dependent in that its magnitude fluctuates with the state of nature through the deterministic function, $\beta(S)$. Following Fei and Schlesinger (2008), we normalize $\beta(\tilde{S})$ by setting its expected value with respect to the cumulative distribution function of $\tilde{S}$ equal to unity. The background risk is state-independent if, and only if, $\beta(S) \equiv 1$ for all realized values of $\tilde{S}$. In contrast to the output price risk, the background

\footnotetext{
${ }^{5}$ Throughout the paper, random variables have a tilde $(\sim)$, while their realizations do not.

${ }^{6}$ In Section 5, we expand the set of hedging instruments to include options.
} 
risk is neither hedgeable nor insurable.

The firm is risk averse and possesses a von Neumann-Morgenstern utility function, $U(\Pi)$, defined over its profit, $\Pi$, at date 1 with $U^{\prime}(\Pi)>0$ and $U^{\prime \prime}(\Pi)<0$ for all $\Pi \geq 0 .{ }^{7}$ The firm's ex-ante decision problem is to choose an output level, $Q \geq 0$, and a futures position, $X$, at date 0 so as to maximize the expected utility of its profit at date 1 :

$$
\max _{Q \geq 0, X} \int_{\underline{S}}^{\bar{S}} \int_{\underline{P}}^{\bar{P}} \int_{\underline{Z}}^{\bar{Z}} U\left[P Q+\left(P^{f}-P\right) X-C(Q)+\beta(S) Z\right] \mathrm{d} H(Z) \mathrm{d} F(P \mid S) \mathrm{d} G(S) .
$$

The first-order conditions for program (1) are given by ${ }^{8}$

$$
\begin{aligned}
\int_{\underline{S}}^{\bar{S}} \int_{\underline{P}}^{\bar{P}} \int_{\underline{Z}}^{\bar{Z}} U^{\prime}\left[P Q^{*}+\right. & \left.\left(P^{f}-P\right) X^{*}-C\left(Q^{*}\right)+\beta(S) Z\right] \\
& \times\left[P-C^{\prime}\left(Q^{*}\right)\right] \mathrm{d} H(Z) \mathrm{d} F(P \mid S) \mathrm{d} G(S)=0
\end{aligned}
$$

and

$$
\begin{aligned}
\int_{\underline{S}}^{\bar{S}} \int_{\underline{P}}^{\bar{P}} \int_{\underline{Z}}^{\bar{Z}} U^{\prime}\left[P Q^{*}+\right. & \left.\left(P^{f}-P\right) X^{*}-C\left(Q^{*}\right)+\beta(S) Z\right] \\
& \times\left(P^{f}-P\right) \mathrm{d} H(Z) \mathrm{d} F(P \mid S) \mathrm{d} G(S)=0,
\end{aligned}
$$

where an asterisk $\left(^{*}\right)$ indicates an optimal level. Solving Eqs. (2) and (3) simultaneously yields the optimal output level, $Q^{*}$, and the optimal futures position, $X^{*}$.

\section{Optimal production}

In the section, we characterize the firm's optimal production decision. To this end, we add Eq. (2) to Eq. (3) to obtain

$$
\int_{\underline{S}}^{\bar{S}} \int_{\underline{P}}^{\bar{P}} \int_{\underline{Z}}^{\bar{Z}} U^{\prime}\left[P Q^{*}+\left(P^{f}-P\right) X^{*}-C\left(Q^{*}\right)+\beta(S) Z\right] \mathrm{d} H(Z) \mathrm{d} F(P \mid S) \mathrm{d} G(S)
$$

\footnotetext{
${ }^{7}$ In this paper, we restrict our attention to state-independent preferences. It is of great interest to extend the analysis to allow for state-dependent preferences along the line of Briys and Schlesinger (1993), Broll and Eckwert (1998), Broll and Wong (2002), and Wong (2012). We leave this challenge for future research.

${ }^{8}$ The second-order conditions for program (1) are satisfied given that $U^{\prime \prime}(\Pi)<0$ and $C^{\prime \prime}(Q)>0$.
} 


$$
\times\left[P^{f}-C^{\prime}\left(Q^{*}\right)\right]=0 .
$$

Given that $U^{\prime}(\Pi)>0$, Eq. (4) reduces to $P^{f}=C^{\prime}\left(Q^{*}\right)$. Hence, we establish our first proposition.

Proposition 1. If the competitive firm can hedge its output price risk exposure by using the futures contracts, the firm optimally chooses its output level, $Q^{*}$, at which the marginal cost of production, $C^{\prime}\left(Q^{*}\right)$, is equated to the predetermined futures price, $P^{f}$, in the presence of the state-dependent background risk.

An immediate implication of Proposition 1 is that the firm's optimal production decision is independent of the utility function, $U(\Pi)$, and of the multiple sources of uncertainty. The separation theorem of Danthine (1978), Feder et al. (1980), and Holthausen (1979) is, therefore, extended to the case wherein there is state-dependent background risk. To see the intuition for Proposition 1, we write the firm's profit at date 1 as

$$
\tilde{\Pi}=P^{f} Q-C(Q)+\left(P^{f}-\tilde{P}\right)(X-Q)+\beta(\tilde{S}) \tilde{Z}
$$

As is evident from Eq. (5), the firm's production decision affects its output price risk exposure only through the third term on the right-hand side of Eq. (5). This term could have been completely eliminated had the firm chosen $X=Q$ within its own discretion. Since

the background risk, $\beta(\tilde{S}) \tilde{Z}$, is exogenous, neither the output price risk nor the background risk is related to the firm's production decision. The firm as such chooses its optimal output level, $Q^{*}$, to be the one that maximizes $P^{f} Q-C(Q)$, leading to the optimality condition, $P^{f}=C^{\prime}\left(Q^{*}\right)$.

\section{Optimal futures hedging}

In this section, we characterize the firm's optimal hedging decision. To focus on the pure hedging motive of the firm, we assume that the futures contracts is unbiased in that 
the futures price, $P^{f}$, is set equal to the unconditional expected value of the output price, $\tilde{P}:$

$$
P^{f}=\int_{\underline{S}}^{\bar{S}} \int_{\underline{P}}^{\bar{P}} P \mathrm{~d} F(P \mid S) \mathrm{d} G(S)
$$

As a benchmark, consider the case that the background risk is state-independent, i.e., $\beta(S) \equiv 1$ for all realized values of $\tilde{S}$. In this benchmark case, we evaluate the left-hand sides of Eq. (3) at $X^{*}=Q^{*}$ to obtain

$$
\int_{\underline{Z}}^{\bar{Z}} U^{\prime}\left[P^{f} Q^{*}-C\left(Q^{*}\right)+Z\right] \mathrm{d} H(Z)\left[P^{f}-\int_{\underline{S}}^{\bar{S}} \int_{\underline{P}}^{\bar{P}} P \mathrm{~d} F(P \mid S) \mathrm{d} G(S)\right]=0,
$$

where the equality follows from Eq. (6). From Eqs. (3) and (7), the optimal futures position is indeed the one that $X^{*}=Q^{*}$ when the background risk is state-independent. Hence, we have the following proposition.

Proposition 2. Given that the futures contracts are unbiased and that the background risk is state-independent, the competitive firm's optimal futures position is a full-hedge, i.e., $X^{*}=Q^{*}$.

It is well-known in the hedging literature that the competitive firm's optimal hedging decision is characterized by the futures position that minimizes the variability of the firm's marginal utility. If the firm opts for a full-hedge, i.e., $X=Q^{*}$, it follows from Eq. (7) that the firm's marginal utility remains stochastic due to the presence of the state-independent background risk, $\tilde{Z}$. However, the expected marginal utility conditional on the realized state is invariant to different realizations of the state of nature:

$$
\frac{\partial}{\partial S} \int_{\underline{Z}}^{\bar{Z}} U^{\prime}\left[P^{f} Q^{*}-C\left(Q^{*}\right)+Z\right] \mathrm{d} H(Z)=0 .
$$

Eq. (8) then implies that the variability of the firm's marginal utility is indeed minimized given the full-hedge. Proposition 2 is consistent with the findings of Briys et al. (1993) that the presence of state-independent background risk does not invalidate the full-hedging theorem of Danthine (1978), Feder et al. (1980), and Holthausen (1979). 
We now resume the general case wherein the background risk is state-dependent. If the full-hedging theorem holds in the presence of the state-dependent background risk, i.e., $X^{*}=Q^{*}$, we must have the following first-order condition:

$$
\int_{\underline{S}}^{\bar{S}} \int_{\underline{Z}}^{\bar{Z}} U^{\prime}\left[P^{f} Q^{*}-C\left(Q^{*}\right)+\beta(S) Z\right] \mathrm{d} H(Z) \int_{\underline{P}}^{\bar{P}}\left(P^{f}-P\right) \mathrm{d} F(P \mid S) \mathrm{d} G(S)=0 .
$$

Note that $\tilde{Z}$ is a zero-mean random variable and that $P^{f}$ is given by Eq. (6). If $U(\Pi)$ is a quadratic function so that $U^{\prime}(\Pi)$ is a linear function, Eq. (9) holds and thus the following proposition invokes.

Proposition 3. Given that the futures contracts are unbiased and that the background risk is state-dependent, the competitive firm's optimal futures position is a full-hedge, i.e., $X^{*}=Q^{*}$, if the firm's preferences are characterized by a quadratic utility function.

Proposition 3 shows that the quadratic specification of $U(\Pi)$ is a sufficient condition for the full-hedging theorem to hold with state-dependent background risk. As convincingly argued by Kimball $(1990,1993)$, prudence is a more reasonable behavioral assumption for decision making under multiple sources of uncertainty. Prudence measures the propensity to prepare and forearm oneself under uncertainty, vis-à-vis risk aversion that is how much one dislikes uncertainty and would turn away from it if one could. Drèze and Modigliani (1972), Kimball (1990), and Leland (1968) show that prudence is both necessary and sufficient to induce precautionary saving. Moreover, prudence is implied by decreasing absolute risk aversion, which is instrumental in yielding many intuitive comparative statics under uncertainty (see Gollier, 2001). The competitive firm is said to be prudent if its utility function satisfies that $U^{\prime \prime \prime}(\Pi)>0$ for all $\Pi \geq 0$.

Following Aboudi and Thon (1995) and Wong (1996), we adopt the concept of regression dependence (see Lehmann, 1966) to describe a tractable covariance structure between the output price, $\tilde{P}$, and the state variable, $\tilde{S}$. Succinctly, $\tilde{P}$ is said to be positively (negatively) regression dependent on $\tilde{S}$ if the conditional cumulative distribution function of $\tilde{P}$ improves (deteriorates) in the sense of first-order stochastic dominance as the realized value of $\tilde{S}$ 
increases, i.e., $F_{S}(P \mid S) \leq(\geq) 0$ for all $(P, S) \in[\underline{P}, \bar{P}] \times[\underline{S}, \bar{S}]$, where the inequality is strict for a non-trivial interval. The positive (negative) regression dependence has the intuition that the two random variables tend to move in the same (opposite) direction. Indeed, the covariance between $\tilde{P}$ and $\tilde{S}$ is positive (negative) if $\tilde{P}$ is positively (negatively) regression dependent on $\tilde{S}$, which is an immediate consequence of Chebyshev inequality (see Shea, 1979). For the ease of exposition, hereafter we order the realizations of the state of nature in a way that $\tilde{P}$ and $\tilde{S}$ are positively correlated in the sense of regression dependence. ${ }^{9}$

Equipped with the concepts of prudence and regression dependence, we state and prove the following proposition.

Proposition 4. Given that the futures contracts are unbiased, that the background risk is state-dependent, and that the output price is positively regression dependent on the state of nature, the competitive firm that is prudent optimally opts for an under-hedge (overhedge), i.e., $X^{*}<(>) Q^{*}$, if the magnitude of the background risk increases (decreases) with an increase in the realized state, i.e., $\beta^{\prime}(S) \geq(\leq) 0$, where the inequality is strict for a non-trivial interval.

Proof. See Appendix A.

The intuition for Proposition 4 is as follows. The competitive firm's optimal futures position, $X^{*}$, is the one that minimizes the variability of the firm's marginal utility. If the firm opts for a full-hedge, i.e., $X=Q^{*}$, it follows from Eq. (9) that the firm's marginal utility remains stochastic due to the presence of the state-dependent background risk, $\beta(\tilde{S}) \tilde{Z}$. If $\beta^{\prime}(S) \geq(\leq) 0$, the magnitude of the background risk enlarges (shrinks) as the realized state becomes higher. Given prudence, i.e., $U^{\prime \prime \prime}(\Pi)>0$, the expected marginal utility conditional on the realized state increases (decreases) with an increase in the realized state in this case:

$$
\frac{\partial}{\partial S} \int_{\underline{Z}}^{\bar{Z}} U^{\prime}\left[P^{f} Q^{*}-C\left(Q^{*}\right)+\beta(S) Z\right] \mathrm{d} H(Z)
$$

\footnotetext{
${ }^{9}$ The case that $\tilde{P}$ and $\tilde{S}$ are negatively correlated in the sense of regression dependence can be easily analyzed in a similar fashion.
} 


$$
=\beta^{\prime}(S) \int_{\underline{Z}}^{\bar{Z}} U^{\prime \prime}\left[P^{f} Q^{*}-C\left(Q^{*}\right)+\beta(S) Z\right] Z \mathrm{~d} H(Z) \geq(\leq) 0
$$

if $\beta^{\prime}(S) \geq(\leq) 0 .{ }^{10} \mathrm{Eq} .(10)$ implies that the variability of the firm's marginal utility is not minimized given the full-hedge. According to Fei and Schlesinger (2008) and Kimball (1990), the firm, being prudent, has an precautionary incentive to shift its profits from the states with small background risk into the states with large background risk. An underhedge (over-hedge) raises (reduces) the firm's profit as the output price increases, which is more likely when the realized state is higher since $\tilde{P}$ and $\tilde{S}$ are positively correlated in the sense of regression dependence. Consequently, such a futures position is more effective in shifting the firm's profits into the states with large background risk if $\beta^{\prime}(S) \geq(\leq) 0$. Doing so reduces the variability of the firm's marginal utility, thereby rendering the optimality of an under-hedge (over-hedge) if $\beta^{\prime}(S) \geq(\leq) 0$.

To illustrate the results in Proposition 4, we consider the following example. Suppose that there are two possible states, i.e., $\tilde{S}$ takes on the low value, $\underline{S}$, with probability $p$, and the high value, $\bar{S}$, with probability $1-p$, where $0<p<1$. We assume that the output price, $\tilde{P}$, is perfectly correlated with $\tilde{S}$ such that $\tilde{P}=\underline{P}$ for sure when $\tilde{S}=\underline{S}$, and $\tilde{P}=\bar{P}$ for sure when $\tilde{S}=\bar{S}$. The background risk is $\beta \tilde{Z}$ if $\tilde{S}=\underline{S}$, and is $(1-\beta) \tilde{Z}$ if $\tilde{S}=\bar{S}$, where $\beta \in[0,1]$ is a constant, and $\tilde{Z}$ is a standard normal random variable. The firm's

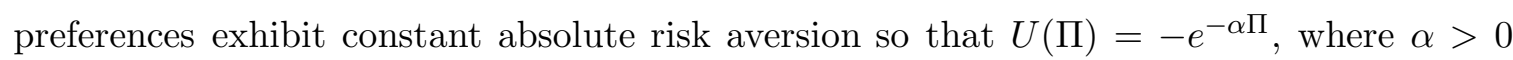
is the constant coefficient of absolute risk aversion. Since the firm's production decision is independent of its hedging decision (see Proposition 1), we fix the firm's output level at $Q^{*}$ and normalize the production cost to zero. The futures contracts are unbiased with the futures price, $P^{f}=p \underline{P}+(1-p) \bar{P}$.

The first-order condition for this two-state example is given by

$$
\begin{aligned}
& p \alpha \mathrm{E}\left\{e^{-\alpha\left[\underline{P} Q^{*}+\left(P^{f}-\underline{P}\right) X^{*}+\beta \tilde{Z}\right]}\right\}\left(P^{f}-\underline{P}\right) \\
& +(1-p) \alpha \mathrm{E}\left\{e^{-\alpha\left[\bar{P} Q^{*}+\left(P^{f}-\bar{P}\right) X^{*}+(1-\beta) \tilde{Z}\right]}\right\}\left(P^{f}-\bar{P}\right)=0,
\end{aligned}
$$

\footnotetext{
${ }^{10} \mathrm{~A}$ formal proof of the sign of Eq. (10) can be found in Appendix A.
} 
where $X^{*}$ is the firm's optimal futures position. Since $P^{f}=p \underline{P}+(1-p) \bar{P}$, Eq. (11) reduces to

$$
e^{-\alpha\left[\underline{P} Q^{*}+\left(P^{f}-\underline{P}\right) X^{*}-\alpha \beta^{2} / 2\right]}=e^{-\alpha\left[\bar{P} Q^{*}+\left(P^{f}-\bar{P}\right) X^{*}-\alpha(1-\beta)^{2} / 2\right]},
$$

where we have used the fact that $\tilde{Z}$ is a standard normal random variable. Solving Eq. (12) yields

$$
X^{*}=Q^{*}-\frac{\alpha}{2}\left(\frac{1-2 \beta}{\bar{P}-\underline{P}}\right)
$$

It is evident from Eq. (13) that $X^{*}<(>) Q^{*}$ if $\beta<(>) 1 / 2$, i.e., if the magnitude of the background risk is larger (smaller) in the high state than in the low state, which is consistent with the results in Proposition 4. On the other hand, if $\beta=1 / 2$ so that the background risk is state-independent, Eq. (13) implies that $X^{*}=Q^{*}$, which is consistent with the results in Proposition 2.

\section{Hedging role of options}

As shown in Proposition 4, the competitive firm, being prudent, deviates from a fullhedge if the magnitude of the background risk varies with changes in the realized state. In this case, the firm retains some residual output price risk exposure because of a precautionary motive. It is thus of great interest to see whether additional hedging instruments, options in particular, may help the firm to achieve better hedge effectiveness.

Let us reconsider the two-state example in Section 4. It is evident from Eq. (12) that the optimal futures position, as given by Eq. (13), is the one that makes the conditional expected marginal utility in the low state equal to that in the high state. The variability of the firm's marginal utility as such is minimized in that no further improvement is plausible, rendering the dominance of the unbiased futures contracts over all other hedging instruments (see Battermann et al., 2000; Briys et al., 1993). 
To show the hedging role of options in the simplest manner, we extend the two-state example by incorporating three possible states. Suppose that $\tilde{S}=S_{i}$ with probability $p_{i}$ for $i=1,2$, and 3 , where $S_{1}<S_{2}<S_{3}, p_{i} \in(0,1)$, and $\sum_{i=1}^{3} p_{i}=1$. The output price, $\tilde{P}$, is perfectly correlated with $\tilde{S}$ such that $\tilde{P}=P_{i}$ for sure when $\tilde{S}=S_{i}$ for $i=1,2$, and 3 , where $0<P_{1}<P_{2}<P_{3}$. The background risk is $\beta_{i} \tilde{Z}$ if $\tilde{S}=S_{i}$ for $i=1,2$, and 3 , where $\beta_{i} \in[0,1]$, $\sum_{i=1}^{3} \beta_{i}=1$, and $\tilde{Z}$ is a standard normal random variable. The firm's utility function is $U(\Pi)=-e^{-\alpha \Pi}$, where $\alpha>0$ is the constant coefficient of absolute risk aversion. The firm's output level is fixed at $Q^{*}$ and the production cost is normalized to zero. The futures contracts are unbiased with the futures price, $P^{f}=\sum_{i=1}^{3} p_{i} P_{i}$. The firm is allowed to trade put option contracts that have a single strike price, $K \in\left(P_{1}, P_{2}\right] .{ }^{11}$ The put option contracts are fairly priced with the premium per contract, $\Phi=\sum_{i=1}^{3} p_{i} \max \left(K-P_{i}, 0\right)=p_{1}\left(K-P_{1}\right)$. Let $X$ and $Y$ be the numbers of the futures and put option contracts sold (purchased if negative) by the firm at date 0 , respectively.

The first-order conditions for this three-state example are given by

$$
\sum_{i=1}^{3} p_{i} \alpha \mathrm{E}\left\{e^{-\alpha\left\{P_{i} Q^{*}+\left(P^{f}-P_{i}\right) X^{*}+\left[\Phi-\max \left(K-P_{i}, 0\right)\right] Y^{*}+\beta_{i} \tilde{Z}\right\}}\right\}\left(P^{f}-P_{i}\right)=0,
$$

and

$$
\sum_{i=1}^{3} p_{i} \alpha \mathrm{E}\left\{e^{-\alpha\left\{P_{i} Q^{*}+\left(P^{f}-P_{i}\right) X^{*}+\left[\Phi-\max \left(K-P_{i}, 0\right)\right] Y^{*}+\beta_{i} \tilde{Z}\right\}}\right\}\left[\Phi-\max \left(K-P_{i}, 0\right)\right]=0,
$$

where $\left(X^{*}, Y^{*}\right)$ is the firm's optimal hedge position. Since $P^{f}=\sum_{i=1}^{3} p_{i} P_{i}$ and $\Phi=$ $\sum_{i=1}^{3} p_{i} \max \left(K-P_{i}, 0\right)$, Eqs. (14) and (15) reduce to

$$
e^{-\alpha\left\{P_{1} Q^{*}+\left(P^{f}-P_{1}\right) X^{*}+\left[\Phi-\left(K-P_{1}\right)\right] Y^{*}-\alpha \beta_{1}^{2} / 2\right\}}=e^{-\alpha\left[P_{2} Q^{*}+\left(P^{f}-P_{2}\right) X^{*}+\Phi Y^{*}-\alpha \beta_{2}^{2} / 2\right]},
$$

and

$$
e^{-\alpha\left[P_{2} Q^{*}+\left(P^{f}-P_{2}\right) X^{*}+\Phi Y^{*}-\alpha \beta_{2}^{2} / 2\right]}=e^{-\alpha\left[P_{3} Q^{*}+\left(P^{f}-P_{3}\right) X^{*}+\Phi Y^{*}-\alpha \beta_{3}^{2} / 2\right]},
$$

\footnotetext{
${ }^{11}$ Because of the put-call parity, payoffs of any combinations of futures, calls, and puts can be replicated by any two of these three financial instruments, thereby rendering one of them to be redundant. Restricting the firm to use only the futures and put option contracts is without any loss of generality.
} 
where we have used the fact that $\tilde{Z}$ is a standard normal random variable. Solving Eqs. (16) and (17) yields

$$
X^{*}=Q^{*}-\frac{\alpha}{2}\left(\frac{\beta_{3}^{2}-\beta_{2}^{2}}{P_{3}-P_{2}}\right)
$$

and

$$
Y^{*}=\left(\frac{P_{2}-P_{1}}{K-P_{1}}\right)\left(X^{*}-Q^{*}\right)+\frac{\alpha}{2}\left(\frac{\beta_{2}^{2}-\beta_{1}^{2}}{K-P_{1}}\right)
$$

which give us the closed form solution to the firm's optimal hedge position, $\left(X^{*}, Y^{*}\right)$.

If $\beta_{1}=\beta_{2}=\beta_{3}$, it is evident from Eqs. (18) and (19) that $X^{*}=Q^{*}$ and $Y^{*}=0$. In this case, the put option contracts are not used by the firm for hedging purposes. Since the background risk is state-independent, Proposition 2 says that the full-hedging theorem holds and thus options play no role as a hedging instrument.

If $\beta_{1}<(>) \beta_{2}=\beta_{3}$, Eqs. (18) and (19) imply that $X^{*}=Q^{*}$ and $Y^{*}>(<) 0$. In this case, the firm adopts a full-hedge, i.e., $X^{*}=Q^{*}$, to completely eliminate the output price risk. ${ }^{12}$ The put option contracts are used due to a precautionary reason that the prudent firm finds it optimal to shift its profit into the states with large background risk. If $S_{1}$ is the state with small (large) background risk, i.e., $\beta_{1}<(>) \beta_{2}=\beta_{3}$, such a precautionary incentive induces the firm to optimally opt for a short (long) put option position, i.e., $Y^{*}>(<) 0$.

If $\beta_{2}<(>) \beta_{3}$, Eq. (18) implies that $X^{*}<(>) Q^{*}$. Substituting Eq. (18) into Eq. (19) yields

$$
Y^{*}=\frac{\alpha}{2}\left(\frac{\beta_{3}^{2}-\beta_{2}^{2}}{K-P_{1}}\right)\left(\frac{\beta_{2}^{2}-\beta_{1}^{2}}{\beta_{3}^{2}-\beta_{2}^{2}}-\frac{P_{2}-P_{1}}{P_{3}-P_{2}}\right)
$$

It is evident from Eq. (20) that $Y^{*} \neq 0$ if $\left(\beta_{2}^{2}-\beta_{1}^{2}\right) /\left(\beta_{3}^{2}-\beta_{2}^{2}\right) \neq\left(P_{2}-P_{1}\right) /\left(P_{3}-P_{2}\right)$. In this case, the prudent firm optimally uses both the futures and put option contracts for hedging and precautionary purposes.

\footnotetext{
${ }^{12}$ The optimality of a full-hedge in this case should not be interpreted as a contradiction to the results in Proposition 4 since the firm also uses the put option contracts for hedging purposes.
} 


\section{Conclusion}

In this paper, we examine the robustness of the separation and full-hedging theorems regarding the behavior of the competitive firm under output price uncertainty $\grave{a}$ la Sandmo (1971) when state-dependent background risk prevails. We show that the separation theorem is unaffected by the introduction of the state-dependent background risk. The fullhedging theorem, on the other hand, holds if either the background risk is state-independent, or the firm's utility function is quadratic. When the firm's preferences exhibit prudence in the sense of Kimball $(1990,1993)$, an under-hedge or an over-hedge is optimal should the magnitude of the background risk vary in a monotonic manner with changes in the realized state. When the prudent firm has access not only to the unbiased futures contracts but also to fairly priced options, we construct a reasonable example wherein the firm optimally uses the options for hedging purposes. This paper thus provides a rationale for the hedging role of options, which is over and above that of futures, in the case of state-dependent background risk.

\section{Acknowledgements}

I would like to thank Udo Broll and Carl Chen (the editor) for their helpful comments and suggestions. The usual disclaimer applies.

\section{Appendix A}

Let the expected value of $\tilde{P}$ conditional on $\tilde{S}=S$ be

$$
\mathrm{E}(\tilde{P} \mid S)=\int_{\underline{P}}^{\bar{P}} P \mathrm{~d} F(P \mid S)=\bar{P}-\int_{\underline{P}}^{\bar{P}} F(P \mid S) \mathrm{d} P
$$

where the second equality follows from integration by parts. Differentiating Eq. (A.1) with 
respect to $S$ yields

$$
\frac{\partial \mathrm{E}(\tilde{P} \mid S)}{\partial S}=-\int_{\underline{P}}^{\bar{P}} F_{S}(P \mid S) \mathrm{d} P \geq 0
$$

since $\tilde{P}$ is positively regression dependent on $\tilde{S}$. It follows from Eqs. (6) and (A.2) that there must exist a critical value, $S^{0} \in(\underline{S}, \bar{S})$, such that $P^{f} \geq \mathrm{E}(\tilde{P} \mid S)$ for all $S \in\left[\underline{S}, S^{0}\right]$ and $P^{f} \leq \mathrm{E}(\tilde{P} \mid S)$ for all $S \in\left[S^{0}, \bar{S}\right]$. Let

$$
V(S)=\int_{\underline{Z}}^{\bar{Z}} U^{\prime}\left[P^{f} Q^{*}-C\left(Q^{*}\right)+\beta(S) Z\right] \mathrm{d} H(Z) .
$$

Differentiating Eq. (A.3) with respect to $S$ yields

$$
\begin{aligned}
& V^{\prime}(S)=\beta^{\prime}(S) \int_{\underline{Z}}^{\bar{Z}} U^{\prime \prime}\left[P^{f} Q^{*}-C\left(Q^{*}\right)+\beta(S) Z\right] Z \mathrm{~d} H(Z) \\
& =\beta^{\prime}(S) \int_{\underline{Z}}^{\bar{Z}}\left\{U^{\prime \prime}\left[P^{f} Q^{*}-C\left(Q^{*}\right)+\beta(S) Z\right]-U^{\prime \prime}\left[P^{f} Q^{*}-C\left(Q^{*}\right)\right]\right\} Z \mathrm{~d} H(Z),
\end{aligned}
$$

where the second equality follows from the fact that $\tilde{Z}$ is a zero-mean random variable. Note that

$$
\frac{\partial U^{\prime \prime}\left[P^{f} Q^{*}-C\left(Q^{*}\right)+\beta(S) Z\right]}{\partial Z}=U^{\prime \prime \prime}\left[P^{f} Q^{*}-C\left(Q^{*}\right)+\beta(S) Z\right] \beta(S)>0
$$

where the inequality follows from prudence, i.e., $U^{\prime \prime \prime}(\Pi)>0$. Hence, $U^{\prime \prime}\left[P^{f} Q^{*}-C\left(Q^{*}\right)\right]>$ $(<) U^{\prime \prime}\left[P^{f} Q^{*}-C\left(Q^{*}\right)+\beta(S) Z\right]$ if $Z<(>) 0$. It then follows from Eq. (A.4) that $V^{\prime}(S) \geq(\leq) 0$ if $\beta^{\prime}(S) \geq(\leq) 0$. Using Eqs. (6), (A.1), and (A.3), we can write the left-hand side of Eq. (9) as

$$
\int_{\underline{S}}^{\bar{S}}\left[V(S)-V\left(S^{0}\right)\right]\left[P^{f}-\mathrm{E}(\tilde{P} \mid S)\right] \mathrm{d} G(S)<(>) 0
$$

where the inequality follows from Eq. (A.2) and $V^{\prime}(S) \geq(\leq) 0$ if $\beta^{\prime}(S) \geq(\leq) 0$. Hence, it follows from Eqs. (3) and (A.6) and the second-order conditions for program (1) that $X^{*}<(>) Q^{*}$. 


\section{References}

Aboudi, R., \& Thon, D. (1995). Second-degree stochastic dominance decisions and random initial wealth with applications to the economics of insurance. Journal of Risk and Insurance, 62, 30-49.

Battermann, H. L., Braulke, M., Broll, U., \& Schimmelpfennig, J. (2000). The preferred hedge instrument. Economics Letters, 66, 85-91.

Briys, E., Crouhy, M., \& Schlesinger, H. (1993). Optimal hedging in a futures market with background noise and basis risk. European Economic Review, 37, 949-960.

Briys, E., \& Schlesinger, H. (1993). Optimal hedging when preferences are state dependent. Journal of Futures Markets, 13, 441-451.

Broll, U., \& Eckwert, B. (1998). Export and hedging decision with state-dependent utility. International Review of Economics and Finance, 7, 247-253.

Broll, U., \& Eckwert, B. (2000). Market structure and multiperiod hedging. International Review of Economics and Finance, 9, 291-298.

Broll, U., \& Wong, K. P. (2002). Optimal full-hedging under state-dependent preferences. Quarterly Review of Economics and Finance, 42, 937-943.

Chavas, J.-P. (1985). On the theory of the competitive firm under uncertainty when initial wealth is random. Southern Economic Journal, 51, 818-827.

Danthine, J.-P. (1978). Information, futures prices, and stabilizing speculation. Journal of Economic Theory, 17, 79-98.

Drèze, J. H., \& Modigliani, F. (1972). Consumption decisions under uncertainty. Journal of Economic Theory, 5, 308-335.

Feder, G., Just, R. E., \& Schmitz, A. (1980). Futures markets and the theory of the firm under price uncertainty. Quarterly Journal of Economics, 94, 317-328.

Fei, W., \& Schlesinger, H. (2008). Precautionary insurance demand with state-dependent 
background risk. Journal of Risk and Insurance, 75, 1-16.

Gollier, C. (2001). The economics of risk and time. Cambridge, MA: Harvard University Press.

Holthausen, D. M. (1979). Hedging and the competitive firm under price uncertainty. American Economic Review, 69, 989-995.

Kimball, M. S. (1990). Precautionary saving in the small and in the large. Econometrica, $58,53-73$.

Kimball, M. S. (1993). Standard risk aversion. Econometrica, 61, 589-611.

Lapan, H., Moschini, G., \& Hanson, S. D. (1991). Production, hedging, and speculative decisions with options and futures markets. American Journal of Agricultural Economics, $73,66-74$

Lehmann, E. L. (1966). Some concepts of dependence. Annals of Mathematical Statistics, 37, 1137-1153.

Leland, H. E. (1968). Saving and uncertainty: The precautionary demand for saving. Quarterly Journal of Economics, 82, 465-473.

Machnes, Y. (1993). Further results on comparative statics under uncertainty. European Journal of Political Economy, 9, 141-146.

Machnes, Y. (1992). Production decisions in the presence of options. International Review of Economics and Finance, 1, 341-345.

Mossin, J. (1968). Aspects of rational insurance purchasing. Journal of Political Economy, $76,553-568$.

Sandmo, A. (1971). On the theory of the competitive firm under price uncertainty. American Economic Review, 61, 65-73.

Shea, G. (1979). Monotone regression and covariance structure. Annals of Statistics, 7, $1121-1126$.

Wong, K. P. (1995). Further results on comparative statics under uncertainty: A comment 
on Machnes. European Journal of Political Economy, 11, 761-768.

Wong, K. P. (1996). Background risk and the theory of the competitive firm under uncertainty. Bulletin of Economic Research, 48, 241-251.

Wong, K. P. (2002). Production decisions in the presence of options: A note. International Review of Economics and Finance, 11, 17-25.

Wong, K. P. (2006). The effects of abandonment options on operating leverage and forward hedging. International Review of Economics and Finance, 15, 72-86.

Wong, K. P. (2007). Operational and financial hedging for exporting firms. International Review of Economics and Finance, 16, 459-470.

Wong, K. P. (2012). Production and hedging under state-dependent preferences. Journal of Futures Markets, 31, in press. 